\title{
WATER QUALITY MANAGEMENT IN INTENSIVE AQUACULTURE IN CHINA
}

\author{
Chengxian $\mathrm{Yu}^{1,2}$, Bin Xing ${ }^{1,2}$, Liying $\mathrm{Xu}^{1,2}$, Daoliang $\mathrm{Li}^{1,2, *}$ \\ ${ }^{\prime}$ College of Information and Electrical Engineering, China Agricultural University, Beijing, \\ China, 100083 \\ ${ }^{2}$ Key Laboratory of Modern Precision Agriculture System Integration, Ministry of Education, \\ Beijing, China, 100083 \\ Corresponding author, Address: P.O. Box 121, EU-China Center for Information \& \\ Communication Technologies, China Agricultural University, 17 Tsinghua East Road, \\ Beijing, 100083, P. R. China, Tel: +86-10-72736717, Fax: +86-10-62737679, Email: \\ li_daoliang@yahoo.com
}

Abstract: Intensive aquaculture is adopted by more and more fish farms in China. This paper focuses on the typical water monitoring and controlling methods in intensive fish culture in Chinese fish farms. The paper illustrates the main factors in fish culturing and the way to control them: dissolved oxygen (DO), temperature, $\mathrm{PH}$, particulate matter and ammonium.

Keywords: intensive aquaculture, fish culture, water quality control

\section{INTRODUCTION}

The history of aquaculture in China goes back at least 2500 years, but from the year 1978 when the open-policy and economic reformations have been adopted, China's aquaculture entered a new era. Then the aquaculture in China developed quickly, and the total output of aquaculture in China reached $5.102 \times 10^{7}$ tons in $2005,70 \%$ and even higher share of total aquatic production in China (National Bureau of Statistics, 2005).

The traditional poly-culture and integrated fish farming has been well known in the world, but it has been challenged by the culture of high value species. For example, land based farming, such as tank culture for flounder

Yu, C., Xing, B., Xu, L. and Li, D., 2008, in IFIP International Federation for Information Processing, Volume 259; Computer and Computing Technologies in Agriculture, Vol. 2; Daoliang Li; (Boston: Springer), pp. 1243-1252. 
is popularized in northeast China. The culture of high value fish is a rapidly expanding field, both in research and industrial aquaculture. A driving force behind this growth is the inherently high value placed upon the products in the marketplace.

The growth of aquaculture has been much contributed by the scientific advancement, such as hatchery techniques, water quality control, breeding technologies, and disease control. Intensive fish farming has a high production per unit area, but on the other hand, large fish farms generate large amounts of particulate organic waste, as well as soluble-inorganic excretory waste (Ackefors and Enell, 1994). This will not only lead to the crack of water quality but also cause seriously environment problems if not properly managed. For this reason, an increased awareness of the consequences of interaction between intensive fish farming and the environment has emerged (Iwama, 1991). To satisfactorily manage the scale of enrichment from fish farming and to ensure that the ecological change does not exceed predetermined levels, monitoring and recycling of water should be regarded as part of a large management framework.

Typical intensive fish culture is conducted in recycling aquaculture systems (RAS). These systems have practical applications in commercial aquaculture hatcheries, in water quality monitoring, in water quality control of fish tanks, and in fish breeding. Water is typically filtered and recycled when there is a specific need to minimize water replacement, to maintain water quality conditions which differ from the supply water, or to compensate for an insufficient water supply. RAS for holding and growing fish have been used by fisheries researchers for more than three decades in western countries but only recent years in China. These systems link the fish culturing tank to the controller of the RAS, which provides for removal of particulate matter, biological filtration, buffering of $\mathrm{pH}$, temperature control, DO control, and water management. As such, "dirty" water flows out of the fish culturing tank, through the RAS for cleaning and sterilization, and returns "clean" to the fish culturing tank as needed. The use of RAS technology enhances bio-security and increases environmental and hydrodynamic control, maximizing production survival and system reliability.

In a typical RAS, there are many water quality variables important for different kind of fishes, but in this paper, only some water quality variables important for most fishes are described. They are removal of particulate matter, biological filtration, buffering of $\mathrm{pH}$, temperature control, DO control, and water management. These processes can be achieved by several separate simple composite units and by several interconnected components, more details will be demonstrated in this paper. 


\section{MATERIALS AND METHOD}

\section{$2.1 \quad$ DO control}

DO is by far the most important chemical parameter in aquaculture. If DO levels in a water body drop too low, fish and other organisms will not be able to survive. Different aquatic plants may impact on DO levels in various ranges.

Low-dissolved oxygen levels are responsible for more fish kills. Fish require oxygen for respiration like humans. The amount of oxygen consumed by the fish is a function of its size, feeding rate, activity level, temperature, and the type of the fish. Small fish may consume more oxygen than large fish because of their higher metabolic rate. Each $18 \mathrm{oF}$ increase in temperature will cause double metabolic rate of the fish, with oxygen requirement much higher.

The amount of oxygen that can be dissolved in water decreases at higher temperatures (Table 1), but decreases with increases in altitudes and salinities. In combining this relationship of decreased solubility with increasing temperatures, it can be seen why oxygen depletion are so common in the summer when higher water temperatures occur.

Table 1. Oxygen dissolved in water at different temperatures

\begin{tabular}{ccc}
\hline Temperature $\left({ }^{\circ} \mathrm{C}\right)$ & \multicolumn{2}{c}{ DO (salinity 32) } \\
\cline { 2 - 3 } & $\mathrm{mL} / \mathrm{L}$ & $\mathrm{mg} / \mathrm{L}$ \\
\hline 0 & 8.21 & 11.74 \\
5 & 7.23 & 10.34 \\
10 & 6.44 & 9.21 \\
15 & 5.79 & 8.28 \\
20 & 5.26 & 7.52 \\
25 & 4.81 & 6.88 \\
30 & 4.43 & 6.33 \\
\hline
\end{tabular}

In conventional fish culture, when summer comes, it may be necessary to supply supplemental aeration to maintain adequate levels of dissolved oxygen. Whereas in recirculation systems the farmer must supply 100 percent of the oxygen needed for the fish and beneficial nitrifying bacteria.

To obtain good growth, fish must be cultured at optimum levels of dissolved oxygen. A good rule of thumb is to maintain DO levels at saturation or at least $4 \mathrm{mg} / \mathrm{L}$. If dissolved oxygen levels become less than $4 \mathrm{mg} / \mathrm{L}$, it can place undue stress on fish; and if DO levels drop to less than $0.6 \mathrm{mg} / \mathrm{L}$ it can result in death (Knowledge of aquaculture).

Fish are not the only consumers of oxygen in aquaculture systems; bacteria and zooplankton consume large quantities of oxygen as well. 
Decomposition of organic materials (algae, bacteria, and fish wastes) is the single greatest consumer of oxygen in aquaculture systems (Figure 1). Problems encountered from water recycling systems usually stem from excessive ammonia production in fish wastes. Consumption of oxygen by nitrifying bacteria that break down toxic ammonia to non-toxic forms depends on the amount of ammonia entering the system.

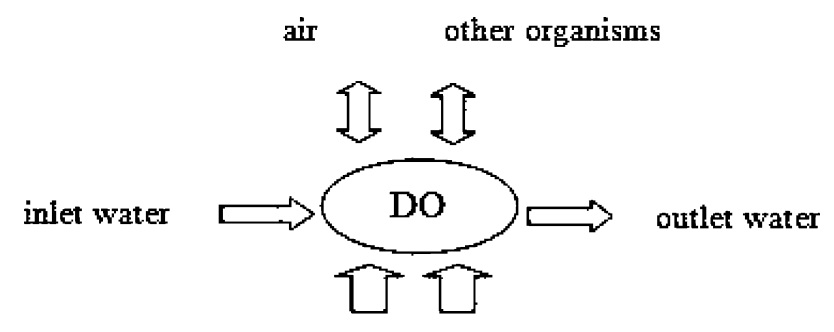

fodder fish

Figure 1. Factors to affect DO in water

Oxygen enters the water primarily through direct diffusion at the air-water interface and through plant photosynthesis. Because of the lack of photosynthesis in indoor water recycling systems, mechanical means of aeration is the only alternative for supplying oxygen to animals cultured in these systems. In RAS oxygen depletions can be calculated, but as predictions may be misleading, these systems should never be substituted for actual measurements. Several forms of mechanical aeration are available to the fish farmers. The general categories are:

Paddlewheels

Venturia pumps

Agitators

Liquid oxygen injection

Impellers

Airlift pumps

Air diffusers

Which aeration should be used depends on the actual environment of the fish farm.

\section{$2.2 \quad$ Temperature control}

After oxygen, water temperature may be the single most important factor affecting the welfare of fish. Fish are cold-blooded organisms and they keep approximately the same temperature as their surroundings. The activity, feeding, growth, and reproduction of all fishes are all affected by water temperature because metabolic rates in fish double for each $18 \mathrm{oF}$ rise in temperature. 
Ideally, species selection of fish farms should be based in part on the temperature of the water supply. Because any attempt to match a fish with less than their ideal temperatures will involve energy expenditures for heating or cooling. This added expense will subsequently increase production costs, so fish farms from different areas usually select different species of fish for the reason of temperature.

The amount of dissolved gases (oxygen, carbon dioxide, nitrogen, etc.) is also determined by water temperature. When the water gets cooler, the gas becomes more soluble. And temperature plays a major role in the physical process called thermal stratification. Water has a high-heat capacity and the density qualities are not unique. In spring, water temperatures are nearly equal at all pond depths. As a result, dissolved gases, nutrients, and fish wastes are evenly mixed throughout the pond. As the days become warmer, the surface water becomes warmer and lighter while the cooler and denser water forms a layer underneath. Because of the different densities between the two layers of water, circulation of the colder bottom water is prevented. In natural fish tanks, dissolved oxygen levels will decrease in the bottom layer as photosynthesis and contact with the air is reduced. The already low oxygen levels are further reduced through decomposition of waste products, which settle to the pond bottom, so farmers use mechanical aeration to circulate the water.

Summer stratification is a greater problem for fish cultured in deeper farm ponds. Localized dissolved oxygen depletion poses a very real problem to fish farmers and stratification may last for several weeks. This condition may develop into a major fish kill when sudden summer rains occur. These rains will cool the warmer upper layer of water enough to allow it to mix with the oxygen poor layer below. Decomposing materials in the oxygenpoor layer are again mixed evenly throughout the pond, resulting in an overall reduction in the dissolved oxygen level. Fish previously able to avoid the oxygen depleted layer are now susceptible to low-dissolved oxygen syndrome and possibly death. To avoid this, there are usually three ways: mechanical aeration, temperature converter, mix warmer water with the tank water by circulating (Figure 2).

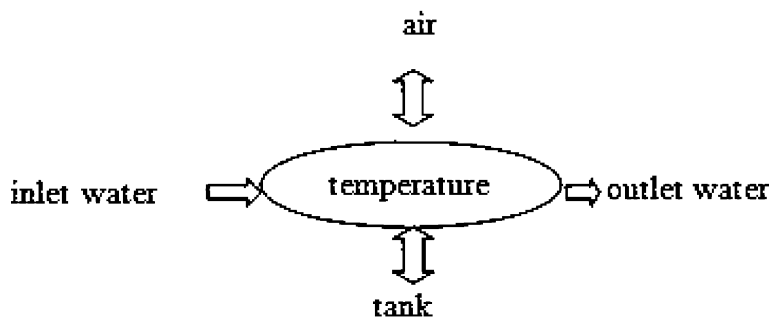

Figure 2. Factors to affect temperature of water 


\subsection{Buffering of $\mathbf{p H}$}

In intensive aquaculture ponds, fish metabolism and bacterial nitrification are the main formation of acids.

The quantity of hydrogen ions $(\mathrm{H}+)$ in water will determine if it is acidic or basic. A value of 7 is considered neutral and values below 7 are considered acidic; above 7, basic. Most fish can tolerate a $\mathrm{pH}$ range of 5-10; however, a range of 6.5-8.5 is preferred for most aquaculture species.

A buffering system to avoid wide swings in $\mathrm{pH}$ is essential in aquaculture. Without some means of storing carbon dioxide released from plant and animal respiration, $\mathrm{pH}$ levels may fluctuate in ponds from approximately 4-5 to over 10 during the day. Figure 3 shows the reason for the change of $\mathrm{PH}$ in culture tanks. In recycling systems constant fish respiration can raise carbon dioxide levels high enough to interfere with oxygen intake by fish, in addition to lowering the $\mathrm{pH}$ of the water. To replace lost alkalinity and sustain the buffering capacity of water, one of the most important substance is carbonate $\left(\mathrm{CO}_{3}^{2-}\right)$, in the form of limestone, bicarbonate of soda, or other common sources is added. Often, bio-filter media (oyster shell) or some other components of the system (concrete tanks) serve as a source of carbonates. Depending on the species cultured, frequent monitoring of water hardness, alkalinity and $\mathrm{pH}$ are required. To avoid fluctuate of $\mathrm{pH}$ levels, carbonate substance or recycling water is required.

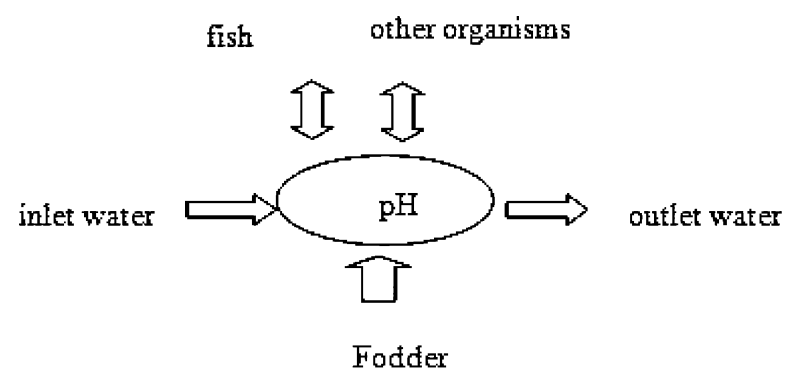

Figure 3. Factors to affect $\mathrm{pH}$ in water

\subsection{Removal of particulate matter}

Large amounts of particulate matter are produced during fish production. As a rule, one pound of fish waste is produced for every pound of fish produced. So suspended fish wastes are a serious concern for RAS. Solids mainly result from fish waste and uneaten feed. The suspended solids can be a major source of poor water quality since they may contain up to 70 percent of the nitrogen load in the system. As they not only irritate the fish's gills, cause several problems to the biological filter, and contribute a portion of the oxygen demand and toxic ammonia in RAS systems, but also promote the 
growth of bacteria that produces-rather than consumes ammonia, they must be concentrated for removal.

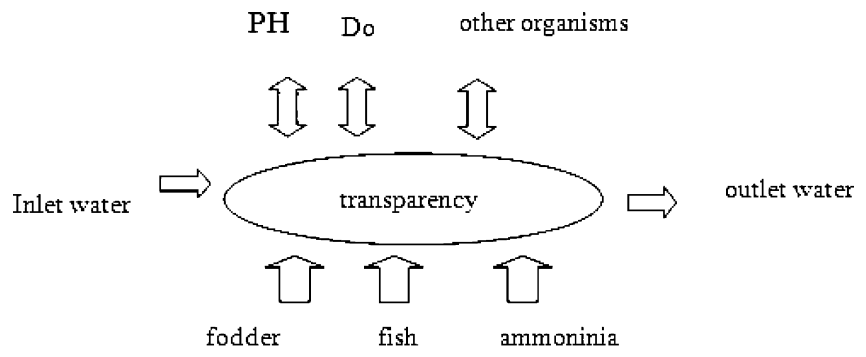

Figure 4. Factors to affect transparency in water

This can be accomplished in the following ways (Figure 4): by having the "dirty" water in settling basins for some time with reduced water turbulence; by medicine which can concentrate the particulate matter to deposits; by mechanical filtration through porous material such as sponge, sand or gravel. Solids that accumulate will gradually be mineralized (broken down) by bacterial action and their volume reduced. The most commonly used method is the settling basins and the mechanical filters. All of the methods require regular cleaning since they are prone to clogging when dirty.

\subsection{Biological filtration}

In RAS, there are many ways ammonia be produced. The most important way is that fish and other aquatic organisms release their nitrogenous wastes primarily as ammonia excreted across the gill membranes. Also, urine, solid wastes, and excess feed have undigested nitrogen fractions, which are additional sources of ammonia. Ammonia is toxic to fish and can result in poor growth and lower resistance to disease.

Fish excrete ammonia and lesser amounts of urea into water as wastes. Two forms of ammonia occur in aquaculture systems, ionized and unionized. The un-ionized form of ammonia $\left(\mathrm{NH}_{3}\right)$ is extremely toxic while the ionized form $\left(\mathrm{NH}_{4}^{+}\right)$is not. Both forms are grouped together as "total ammonia" (Figure 5).

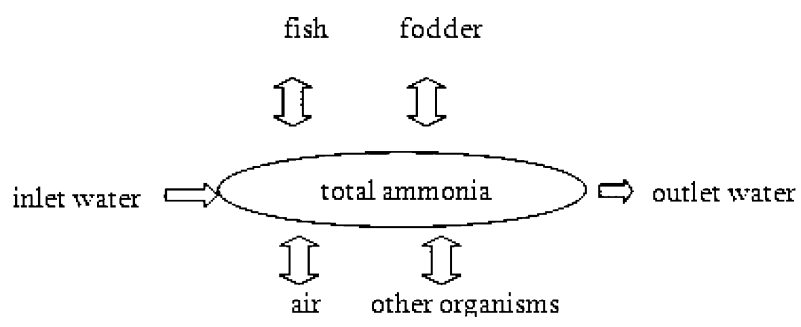

Figure 5. Factors to affect total ammonia in water 
To reduce the amount of total ammonia, bio-filters which keep bacteria in them are usually used. The bacteria responsible for these reactions can be easily inoculated into bio-filters from soil and water environments, or with material from established filters. Keeping bacterial populations sufficient to remove ammonia and nitrite at rates is required during operation. So a biofilter is typically conditioned for several weeks by adding ammonia and monitoring its breakdown prior to stocking fish.

To control ammonia levels in recycling water systems, extensive surface area is provided for bacteria which biologically oxidize ammonia to relatively harmless nitrate $\left(\mathrm{NO}_{3}^{-}\right)$. The process of bacterial nitrification adds additional oxygen demand to the system, so high dissolved oxygen levels are required. Bacterial nitrification is a two-stage process resulting first in the transformation of ammonia to nitrite $\left(\mathrm{NO}_{2}{ }^{-}\right)$, then a further oxidation of nitrite to nitrate. Nitrite is also toxic to fish at low concentrations; hence, both reactions must occur for successful bio-filtration. Through biological processes, toxic ammonia can be degraded to harmless nitrates.

Media for bio-filters can be virtually any substrate which provides maximum surface area for bacterial growth: oyster shell, gravel, nylon netting, plastic rings, and sponge foam pads are among popular choice. In designing bio-filters, the principal concerns should be maximum surface area for bacterial growth, high dissolved oxygen levels, uniform water flow through the filter, sufficient void space to prevent clogging, and proper sizing to ensure adequate ammonia removal capability. As filter surface area, fish density, and water flow are all important considerations, required size of a bio-filter is difficult to predict.

Nitrification is typically carried out in a variety of systems, which can be grouped into six general types: submerged filters, trickling filters, reciprocating filters, rotating biological contactors ( $\mathrm{RBC}$ ), rotating drums, and fluidized bed reactors (Wheaton et al., 1991). A number of comparative studies of these systems have been conducted and RBCs were found to give the best performance with respect to specific ammonia removal efficiency (ammonia removal per surface area per time). However, due to operating problems with RBCs, often related to shaft and bearing failures, their commercial use has been limited.

\section{CONCLUSION AND DISCUSSION}

RAS have good performances in China aquaculture, and farmers benefit a lot from these systems. But these systems have their inefficiencies as well. Recycling water systems should be designed for simplicity of operation and 
economic feasibility. Sufficient time must be allowed for conditioning of the bio-filter prior to introducing fish. Ammonia and nitrite concentrations must be checked frequently. Dissolved oxygen should be sustained above $60 \%$ of saturation and periodically verified. Alkalinity, hardness, and $\mathrm{pH}$ need to be measured and adjusted, if necessary, at regular intervals. Filters should be inspected and cleaned as required. Frequent monitoring of the performance of the recycling system will allow the manager to improve and refine its operation over time. As the factors mentioned above, a new kind of RAS is required, which will automatically monitor these water quality parameters, auto control the equipments to adjust water quality parameters to the proper level. And all the parameter level will be computed in a model base on the knowledge of separate kind of fish (Figure 6). This will come true in three years in Fengze Company in Lijin, Dongying of China.

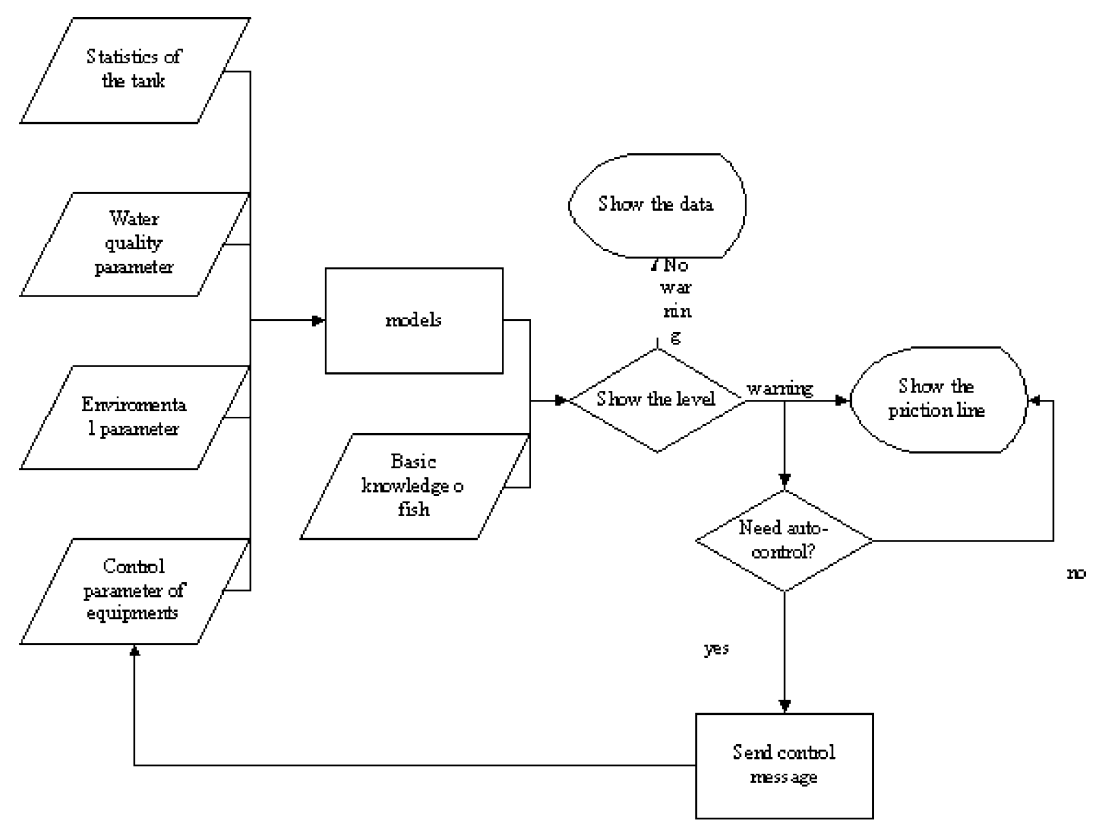

Figure 6. Structure of the system

\section{ACKNOWLEDGEMENTS}

We thank the members from Southern Regional Aquaculture Center for their data. And thank Fengze Company for their help of offering us the opportunity to do some research in their company. 


\section{REFERENCES}

Ackefors, H., Enell, M., 1994. The release of nutrient and organic matter from aquaculture systems in Nordic countries. J. Appl. Ichthyol. 10, 225-241.

Iwama, G.K., 1991. Interactions between aquaculture and the environment. Crit. Rev. Environ, Contr. 21, 177-216.

National Bureau of Statistics, China Statistical Yearbook, China Statistics Press, 2005.

Knowledge of aquaculture http://www.instrument.com.cn/netshow/SH100886/C15717.htm

Wheaton, F., Hochheimer, J. and Kaiser, G.E., 1991. Fixed film nitrification filters for aquaculture. In: D.E. Brune and J.R. Tomasso (Editors), Aquaculture and Water Quality. World Aquacult. Sot., Baton Rouge, LA, pp. 272-303. 